\title{
RANCANG BANGUN RESPONSIVE WEB LAYOUT DENGAN MENGGUNAKAN BOOTSTRAP FRAMEWORK
}

\author{
Ahmad Zakir \\ Teknik Informatika Sekolah tinggi Teknik Harapan Medan \\ Jl.HM Joni No 70 A Medan 20152 Indonesia \\ suratzakir@gmail.com
}

\begin{abstract}
Abstrak - Internet sebagai salah satu media informasi yang dapat diakses setiap orang kapan saja dan dimana saja, saat ini internet telah menjadi salah satu kebutuhan masyarakat dalam memperoleh informasi, hal ini didukung oleh perkembangan berbagai perangkat seperti, tablet dan smartphone yang semakin memudahkan banyak orang untuk mengakses informasi. Untuk mendukung berbagai perangkat dalam mengakses informasi (website) melalui internet maka aplikasi harus menyesuaikan dengan perangakat yang digunakan terutama dalam hal pengelolaan layout web. Web layout merupakan salah satu bagian terpenting yang harus direncanakan dengan baik agar website dapat berjalan dengan baik, cepat dan dapat dengan mudah diakses oleh berbagai macam browser serta dapat berjalan diberbagai macam flatform. Bootstrap merupakan sebuah framework yang dapat menyelesaikan permasalahan dalam mendesain sebuah layout web yang responsive.
\end{abstract}

Keywords - Web Responsive, Bootstrap, Teknologi Web Desain.

\section{PENDAHULUAN}

Teknologi informasi saat ini berkembang dengan pesat di berbagai bidang kehidupan manusia. Penggunaan internet saat ini dirasakan manfaatnya dalam berbagai bidang dan seluruh lapisan masyarakat khusunya teknologi web. Tantangan baru teknologi web khususnya untuk para penyedia informasi adalah bagaimana menyajikan informasi dengan cepat, tepat dan mudan dijangkau oleh seluruh lapisan masyarakat serta dapat diakses oleh berbagai media dan dengan berbagai flatform.

Menurut lembaga riset pasar e-Marketer, populasi pengguna internet di Indonesia mencapai 83,7 juta orang pada 2014. Angka yang berlaku untuk setiap orang yang mengakses internet setidaknya satu kali setiap bulan itu mendudukkan indonesia di peringkat ke-6 terbesar di dunia dalam hal jumlah pengguna internet. Pada 2017, e-Marketer memperkirakan pengguna internet di Indonesia bakal mencapai 112 juta orang, mengalahkan Jepang di peringkat ke-5 yang pertumbuhan jumlah pengguna internetnya lebih lamban. Pada tahun 2018, diperkirakan sebanyak 3,6 miliar manusia di bumi bakal mengakses internet setidaknya sekali tiap satu bulan.

Rancang bangun web layout merupakan salah satu faktor utama yang harus direncanakan dengan baik agar website dapat berjalan dengan baik, cepat dan dapat diakses oleh berbagai macam browser serta dapat berjalan diberbagai macam flatform. Bootstrap merupakan sebuah framework yang dapat menyelesaikan permasalahan dalam mendesain web. Slogan dari framework ini adalah "Sleek, intuitive, and powerful front-end framework for faster and easier web development", yang berarti kita dapat mendesain sebuah website dengan lebih rapi, cepat dan mudah.
Selain itu Bootstrap juga responsive terhadap banyak platform, artinya tampilan halaman website yang menggunakan Bootstrap ini akan tampak tetap rapi, baik versi mobile maupun desktop.

\section{METODE DAN PERANCANGAN}

Twiter Boostrap merupakan kerangka font-end yang berfungsi untuk pengembangan responsive web layout lebih cepat dan lebih mudah. Dalam merancang bangun responsive web layout ada beberapa hal yang harus diketahui didalam penggunaan Framewok Bootstrap yaitu:

1. Mobile first approach

Framework bootstrap fokus utama terhadap pendekatan layout berbasis ponsel

2. Browser support

Bootstrap didukung oleh semua browser populer seperti Firefox, Google Chrome, Internet Explorer, Opera, Safari dan browser-browser lainnya.

3. Knowledge to get started

HTML dan CSS merupakan pengetahuan dasar yang hasus dimiliki agar dapat menggunakan Framework Bootstrap.

4. Responsive desain Bootsraps responsive CSS yang dibangun dapat menyesuaikan tapilan layar desktop, tablet dan mobiles.

Beberapa paket yang terdapat didalam framework bootstrap yaitu:

1. Scaffolding

Struktur Framework Bootstrap menyediakan struktur dasar dengan Grid System, link style dan background.

2. CSS (Cascading Style Sheets)

Framework Bootsrap menampilkan pengaturan CSS secara global, elemen dasar HTML ditata dan 
ditingkatkan dengan extensible class dan advanced grid system.

3. Components

Bootstrap memiliki banyak komponen yang dapat digunakan kembali seperti penggunaan navigasi, dropdowns, alert dan lain-lain.

4. Javascript plugins

Bootstrap juga memilikai banyaka plugin jQuery yang dapat digunakan dan dapat dimodifikasi sesuaikan dengan kebutuhan.

5. Customize

Komponen-komponen yang terdapat Bootstrap dan plugin jQuery dapat dirubah atau dikembangkan kedalam versi terbarunya.

\section{A. Ruang Lingkup Struktur File}

Terdapat beberapa struktur file didalam Bootstrap framework yaitu :

1. Precompiled Bootstrap

Berikut ini adalah struktur file / direktori pada Framework Bootsrap :

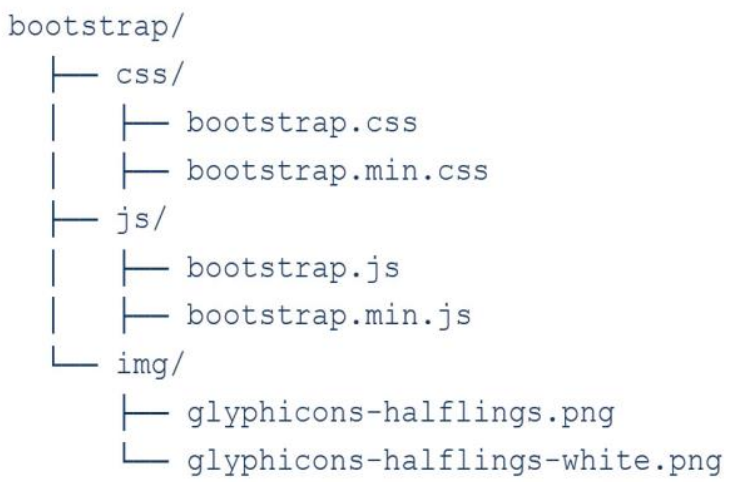

2. Bootstrap Source Code

Berikut ini adalah source code struktur file / direktori pada Framework Bootsrap :

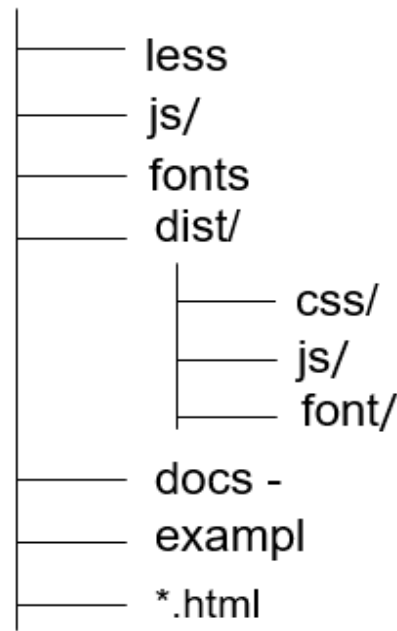

\section{B. Bootstrap Grid System}

Grid System pada bootstrap merupakan pengaturan ukuran yang di tampilkan pada monitor. grid system berfungsi untuk membuat pengaturan untuk lebar dari masing-masing komponen web sehingga kita dapat dengan bebas mengatur ke-responsivan halaman website yang kita buat dengan bootstrap. Bootstrap memiliki 12 grid. yang nantinya kita akan dapat menggunakan class berikut ini untuk mengatur keresponsive an halaman website dengan mengaturnya menggunakan 12 grid bootstrap. Bootstrap memiliki beberapa class grid yang masing-masing nya memiliki kegunaannya masing-masing.

Berikut ini Bootstrap Grid System :

1. col-lg-*

Digunakan untuk mengatur grid pada monitor komputer yang berukuran besar.

2. col-md-*

Digunakan untuk mengatur grid pada layar monitor komputer yang berukuran sedang.

3. col-sm-*

Digunakan untuk mengatur grid pada monitor yang berukuran tablet.

4. col-xs-*

Digunakan untuk mengatur grid untuk ukuran handphone.

\section{$<!$ DOCTYPE html $>$}

$<$ html $>$

$<$ head $>$

$<$ title>Bootstrap Part 16 : Mengenal Grid System Bootstrap $</$ title $>$

$<$ link rel="stylesheet" type="text/css"

href="css/bootstrap.css">

<script type="text/javascript" src="js/jquery.js" $></$ script $>$

$<$ script type $=$ "text/javascript"

src="js/bootstrap.js" $></$ script $><$ style type="text/css" $>$

$\operatorname{div}\{$

background: \#2ea3f2;

text-align: center;

border: 1px solid \#fff;

padding: 10px;

color: \#fff;

\}

$</$ style $>$

$</$ head $>$

$<$ body $>$

$<$ center $><$ h1 $>$ Mengenal Grid System Bootstrap

www.malasngoding.com $\langle/$ h1 $></$ center $>$

$\langle\mathrm{br} />$

$\langle$ div class="col-md-12" $>$.col-md-12</div $\rangle$

$\langle$ div class="col-md-6" $>$.col-md- $6</$ div $>$

$<$ div class="col-md-6" $>$.col-md- $6</$ div $>$

$\langle$ div class="col-md-4" $>$.col-md-4</div $>$

$\langle$ div class="col-md-4" $>$.col-md-4</div $\rangle$

$\langle$ div class=" col-md-4" $>$.col-md- $4</$ div $\rangle$

$\langle$ div class="col-md-3" $>$.col-md-3 $\langle/$ div $\rangle$

$\langle$ div class="col-md-3" $>$.col-md-3 $</$ div $\rangle$

$<$ div class=" col-md-3" $>$.col-md-3 $</$ div $>$

$<$ div class="col-md-3" $>$.col-md-3 $</$ div $>$

$\langle$ div class=" col-md-2" $>$.col-md-2</div $\rangle$ 
$\langle$ div class="col-md-2" $>$.col-md-2 $\langle/$ div $\rangle$ $\langle$ div class="col-md-2" $>$.col-md-2 $\langle/$ div $\rangle$ $\langle$ div class="col-md-2" $>$.col-md-2 $\langle/$ div $\rangle$ $\langle$ div class="col-md-2" $>$.col-md- $2</$ div $\rangle$ $\langle$ div class="col-md-2" $>$.col-md- $2</$ div $\rangle$ $\langle$ div class="col-md-1" $>$.col-md- $1</$ div $\rangle$ $\langle$ div class="col-md-1" $>$.col-md- $1</$ div $\rangle$ $\langle$ div class="col-md-1" $>$.col-md- $1</$ div $\rangle$ $\langle$ div class="col-md-1" $>$.col-md-1 $</$ div $\rangle$ $\langle$ div class="col-md-1" $>$.col-md-1 $</$ div $\rangle$ $\langle$ div class="col-md-1" $>$.col-md-1 $</$ div $\rangle$ $\langle$ div class="col-md-1" $>$.col-md-1 $</$ div $\rangle$ $\langle$ div class="col-md-1" $>$.col-md-1 $</$ div $\rangle$ $\langle$ div class="col-md-1" $>$.col-md-1 $</$ div $\rangle$ $\langle$ div class="col-md-1" $>$.col-md-1 $</$ div $\rangle$ $\langle$ div class="col-md-1" $>$.col-md- $1</$ div $\rangle$ $\langle$ div class="col-md-1" $>$.col-md- $1</$ div $\rangle$ $</$ body $>$ $</$ html $>$

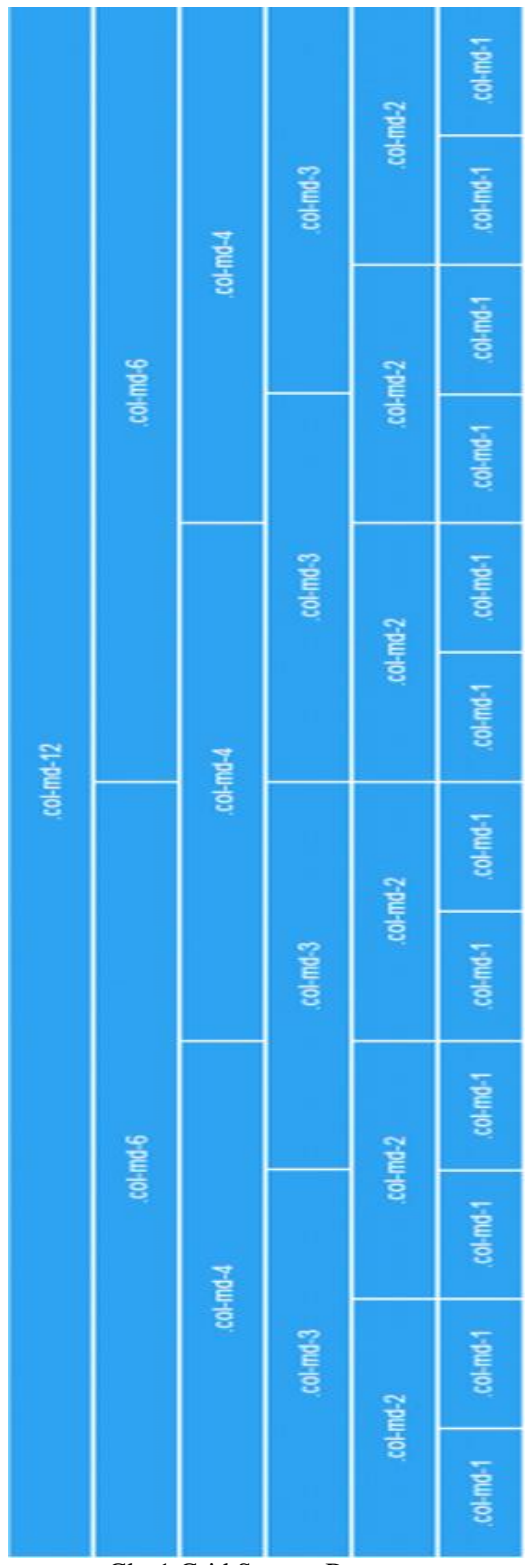

Gbr.1 Grid System Bootsrap

\section{HTML Template}

Berikut ini template HTML dasar menggunakan Bootstrap akan terlihat seperti dibawah ini : $<$ htm1 <head

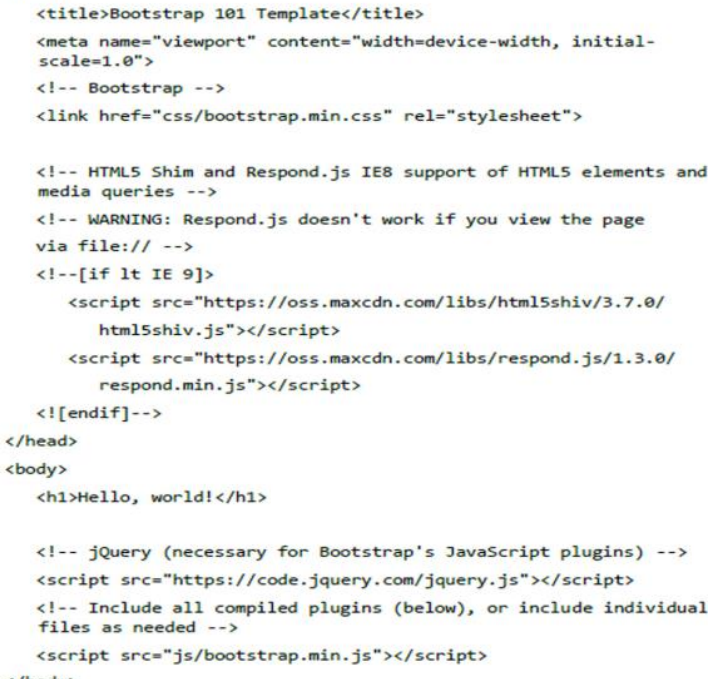

\section{HASIL DAN PEMBAHASAN}

A. Bootstrap Grid Option

Tabel berikut merangkum aspek bagaimana sistem grid Bootstrap bekerja di beberapa perangkat:

TABEL I

BOOTSTRAP GRID SISTEM

\begin{tabular}{|c|c|c|c|c|}
\hline & $\begin{array}{l}\text { Extra small } \\
\text { devices Phones } \\
(<768 \mathrm{px})\end{array}$ & $\begin{array}{l}\text { Small devices } \\
\text { Tablets ( } \geq 768 \mathrm{px})\end{array}$ & $\begin{array}{l}\text { Medium devices } \\
\text { Desktops ( (־992px) }\end{array}$ & $\begin{array}{l}\text { Large devices } \\
\text { Desktops } \\
(\unrhd 1200 \mathrm{px})\end{array}$ \\
\hline Grid behavior & $\begin{array}{l}\begin{array}{l}\text { Horizontal at all } \\
\text { times }\end{array}\end{array}$ & $\begin{array}{|lr|}\begin{array}{l}\text { Collapsed to start, } \\
\text { horizontal above } \\
\text { breakpoints }\end{array} \\
\end{array}$ & $\begin{array}{ll}\text { Collapsed to start, } \\
\text { horizontal above } \\
\text { breakpoints }\end{array}$ & $\begin{array}{l}\text { Collapsed to start, } \\
\text { horizontal above } \\
\text { breakpoints }\end{array}$ \\
\hline $\begin{array}{l}\text { Max container } \\
\text { width }\end{array}$ & \begin{tabular}{|l} 
None (auto) \\
\end{tabular} & $750 \mathrm{px}$ & \begin{tabular}{|l|} 
970px \\
\end{tabular} & $1170 \mathrm{px}$ \\
\hline Class prefix & .col-xs- & col-sm- & .col-md- & .col-lg- \\
\hline \# of columns & 12 & 12 & 12 & 12 \\
\hline Max column width & Auto & \begin{tabular}{|l|}
$60 \mathrm{px}$ \\
\end{tabular} & $78 \mathrm{px}$ & $95 \mathrm{px}$ \\
\hline Gutter width & $\begin{array}{l}\text { 30px (15px on each } \\
\text { side of a column) }\end{array}$ & $\begin{array}{l}\text { 30px (15px on each } \\
\text { side of a column) }\end{array}$ & $\begin{array}{l}\text { 30px (15px on each } \\
\text { side of a column })\end{array}$ & $\begin{array}{l}30 \mathrm{px} \text { ( } 15 \mathrm{px} \text { on each } \\
\text { side of a column }\end{array}$ \\
\hline Nestable & Yes & Yes & Yes & Yes \\
\hline Offsets & Yes & Yes & Yes & Yes \\
\hline Column ordering & Yes & Yes & Yes & Yes \\
\hline
\end{tabular}

\section{B. Responsive Utilities}

Bootstrap memberikan beberapa bantuan untuk pengembangan perangkat lunak, ini dapat digunakan untuk menampilkan dan menyembunyikan konten didalam perangkat melalui permintaan media yang dikombinasikan dengan perangkat yang miliki layar berukuran besar, kecil dan menengah.

TABEL II

RESPONSIVE UTILITIES

\begin{tabular}{|l|l|}
\hline Classes & Devices \\
\hline $\begin{array}{l}\text {.visible-Xs } \\
\text {.visible-sm }\end{array}$ & $\begin{array}{l}\text { Extra small (less than 768px) visible } \\
\text { Small (up to 768 px) visible }\end{array}$ \\
\hline .visible-md & Medium (768 px to 991 px) visible \\
\hline .visible-lg & Larger (992 px and above) visible \\
\hline .hidden-xs & Extra small (less than 768px) hidden \\
\hline .hidden-sm & Small (up to 768 px) hidden \\
\hline .hidden-md & Medium (768 px to 991 px) hidden \\
\hline .hidden-lg & Larger (992 px and above) hidden \\
\hline
\end{tabular}




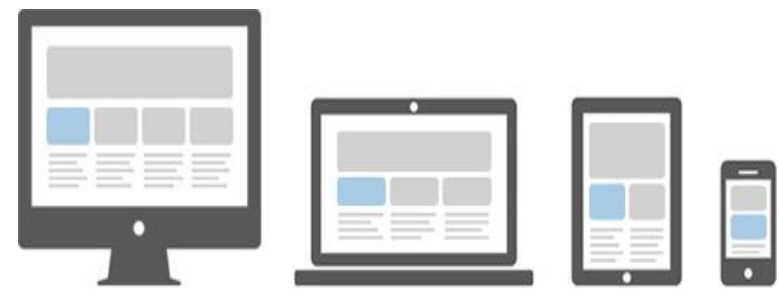

Gbr.2 Responsive Design Illustration

\section{KESIMPULAN}

Kesimpulan yang penulis ambil dari pembahasan diatas adalah sebagai berikut:

1. Kerangka framework Bootstrap dibangun menggunakan Less, sebuah teknologi CSS yang sederhana dan mudah untuk digunakan. Less juga menawarkan lebih banyak kekuatan dan fleksibilitas dari CSS pada umumnya. Dengan Less, pengembang dapat mengakses dengan mudah informasi dan fungsi warna, variabel, dan operasi penggunaan.

2. Responsive layout dan 12 column grid system. Dengan responsive layout maka aplikasi web yang didesain dengan menggunakan Bootstrap akan langsung menyesuaikan dengan lebar dari media perambahnya. Sehingga tampilan web akan tetap rapih dibuka dengan media apapun baik itu handphone, tablet, laptop ataupun PC desktop. Jadi, tampilan tidak akan terganggu dengan resolusi dari layar. Sedangkan 12-column grid system sederhananya adalah Bootstrap akan membagi lebar layar menjadi 12 bagian. Sehingga pembagian kolom per kolom tampilan web akan menjadi lebih mudah

\section{REFERENSI}

[1] Alatas, Husein. 2013. Responsive Web Design dengan PHP dan Bootstrap. Yogyakarta: Loko Media

[2] Birminggham. 2013. Responsive Web Design by Example Beginner's Guide. UK: Packt Publishing Ltd.

[3] Jonathan Fielding. 2014. Beginning Responsive Web Design with HTML5 and CSS3. New York: Apress Media

[5] http://www.tutorialspoint.com/bootstrap/index.html

[6] http://getbootstrap.com/

[7] http://tekno.kompas.com/read/2014/11/24/07430087/

Pengguna.Internet.Indonesia.Nomor.Enam.Dunia 